\title{
Effective Monitoring of Odor Pollution in Urban Area
}

\author{
Park Chan Jin
}

\begin{abstract}
To investigate the methods of making more comfortable air quality in urban area, the effective methods of monitoring odor pollution were compared to suggest most adequate solution. At first, the definitions of odor concentration with sensor intensity and odor dilution ratio were explained and the on line monitoring of instrumental analysis with the defined odor components were explained. Three different methods of on-line monitoring various odor sources especially to make instant monitoring with on-line processing were analyzed with several illustrations of case facilities. And some modified systems of on-line monitoring of major odor components were suggested.
\end{abstract}

Index Terms-Air quality, odor pollution, on-line monitoring.

\section{INTRODUCTION}

Economic development in recent years has brought many changes in urban life with various air pollution symptoms neighboring industrial complex and landfill regions. Air pollution like sulfur oxides, nitrogen oxides and particulate does not have direct effects on human health below environmental standard concentrations, and is monitored with on-line monitoring system with accurate mechanism.

Odor is special scope of air pollution which can make dislike feeling or unpleasant taste in the air and water below law standards. And this feeling of disgust is different from one person to another one. For example, a barrister with various coffee making does not like good taste of making coffee. In this study, the effective methods of monitoring of odor pollution in urban area were investigated to keep air quality clean.

\section{ODOR CONCENTRATION}

In order to compare the effective methods of odor monitoring, the definitions of odor concentration must be compared.

\section{A. Odor Intensity}

Human nose is the most convenient and precise instrument for detecting odorous smell. Therefore six intensities of odor strength are defined to determine the odor concentrations. Table I is illustrated to show this odor intensity.

\section{B. Odor Dilution Ratio}

This method is used to determine more accurate odor concentration using the dilution methods by five qualified personels in the clean laboratory with no odors. Sampling of odor is done outside of odor generating region and is carried

Manuscript received December 12, 2013; revised January 15, 2014.

Park Chan Jin is with School of Urban \& Environmental Eng., Incheon National University (e-mail: cjpark@incheon.ac.kr). within 48 hours after sampling in the source areas.

\begin{tabular}{|c|c|c|}
\multicolumn{2}{|c|}{ TABLE I: THE INTENSITY OF SENSORY ODORS } \\
\hline Intensity & \multicolumn{2}{|c|}{ State of odor sensitivity } \\
\hline 0 & No odors & None \\
1 & Limit value of odors & Threshold \\
2 & Kind of odors & Moderate \\
3 & Strong odors & Strong \\
4 & Very strong odors & Very Strong \\
5 & Over stong odors & Over Strong \\
\hline
\end{tabular}

\section{ON-LINE MONITORING}

Because of inconvenience measuring odor components with simultaneous generation and with many components, on-line odor monitoring system has been developed very actively in Korea [1], [2]. First type is to measure all odor components with standard analyzing methods as given in Table I, and the second one is to integrate many odor components like Table II into one signal as shown in Fig. 1 [3].

\begin{tabular}{|c|c|c|c|c|c|}
\hline & Component & $\begin{array}{l}\text { Standard } \\
\text { (ppm) }\end{array}$ & $\begin{array}{l}\text { Minimum } \\
\text { (ppm) }\end{array}$ & $\begin{array}{c}\text { Maximum } \\
(\mathrm{ppm})\end{array}$ & $\begin{array}{l}\text { Mean } \\
(\mathrm{ppm})\end{array}$ \\
\hline 1 & Acetaldehyde & $0.05 \sim 0.1$ & 0 & 0.0028 & 0.0005 \\
\hline 2 & iso-Valeraldehyde & $\begin{array}{c}0.003 \\
\sim 0.006\end{array}$ & 0 & 0.0003 & 0.0000 \\
\hline 3 & n-Butyraldehyde & $0.029 \sim 0.1$ & 0 & 0 & 0.0000 \\
\hline 4 & n-Valeraldehyde & $0.009 \sim 0.02$ & 0 & 0.0023 & 0.0000 \\
\hline 5 & Propionaldehyde & $0.05 \sim 0.1$ & 0 & 0.0002 & 0.0000 \\
\hline 6 & Ammonia & $1 \sim 2$ & 0.0068 & 0.0326 & 0.0209 \\
\hline 7 & TM-amine & $0.005 \sim 0.02$ & 0 & 0 & 0.0000 \\
\hline 8 & Butylic Acid & $\begin{array}{l}0.001 \sim \\
0.002\end{array}$ & 0 & 0.0083 & 0.0007 \\
\hline 9 & iso-Valeric Acid & $\begin{array}{c}0.001 \sim \\
0.004\end{array}$ & 0 & 0.0272 & 0.0017 \\
\hline 10 & n-Valeric Acid & $\begin{array}{c}0.0009 \sim \\
0.002\end{array}$ & 0 & 0.0501 & 0.0030 \\
\hline 11 & propionic Acid & $0.03 \sim 0.07$ & 0 & 0.0003 & 0.0001 \\
\hline 12 & Dimethyldisulfide & $0.009 \sim 0.03$ & 0 & 0.0006 & 0.0000 \\
\hline 13 & Dimethylsulfide & $0.01 \sim 0.05$ & 0 & 0.0018 & 0.0000 \\
\hline 14 & $\mathrm{H}_{2} \mathrm{~S}$ & $0.02 \sim 0.06$ & 0 & 0.0075 & 0.0003 \\
\hline 15 & Methylmercaptane & $\begin{array}{c}0.002 \sim \\
0.004\end{array}$ & 0 & 0.0012 & 0.0000 \\
\hline 16 & Butyl acetate & $1 \sim 4$ & 0 & 0.0010 & 0.0000 \\
\hline 17 & isobuthylalcohol & $0.9 \sim 4$ & 0 & 0.0024 & 0.0000 \\
\hline 18 & $\begin{array}{c}\text { Methyl } \\
\text { Ethylketone }\end{array}$ & $13 \sim 35$ & 0 & 0.0259 & 0.0012 \\
\hline 19 & $\begin{array}{c}\text { Methylisobutyl } \\
\text { ketone }\end{array}$ & $1 \sim 3$ & 0 & 0.0259 & 0.0001 \\
\hline 20 & o-xylene & $1 \sim 2$ & 0 & 0.0052 & 0.0002 \\
\hline 21 & Stylene & $0.4 \sim 0.8$ & 0 & 0.0024 & 0.0001 \\
\hline 22 & Toluene & $10 \sim 30$ & 0 & 0.1558 & 0.0112 \\
\hline
\end{tabular}


On-line odor monitoring system operates 24 hours per day. And the technique is combined with IT(Information Technology) and UT(Ubiquitous Technology).

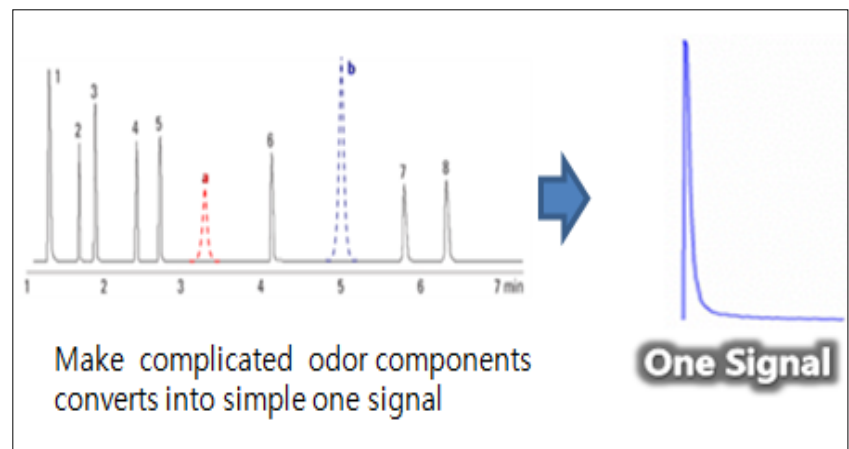

Fig. 1. The sensory odor signal process.

This system can have immediate response to civil appeals of odors, if accuracy of component concentration is taken security. As the odor plume moves rapidly, it can be recorded as single values with the on-line system. Another strongpoint is that the trajectory of odor motion can be achieved which is the cause of civil appeals. And sampling of odors at the highest concentration and at the night time could be possible.

\section{Ubiquotous Monitoring}

Electronic odor sensor is used to measure odor concentration of emission sources to make on-line real time management by the government or other managing system like Fig. 2 [3]. This system is operated by making electronic signal proportional to odor concentrations, therefore the periodical confirmation of accuracy is very important [4], [5]. The database of odor emission factory is related to weather measuring data with wind fields data to make clear which factory is responsible for the civil appeals of odors.

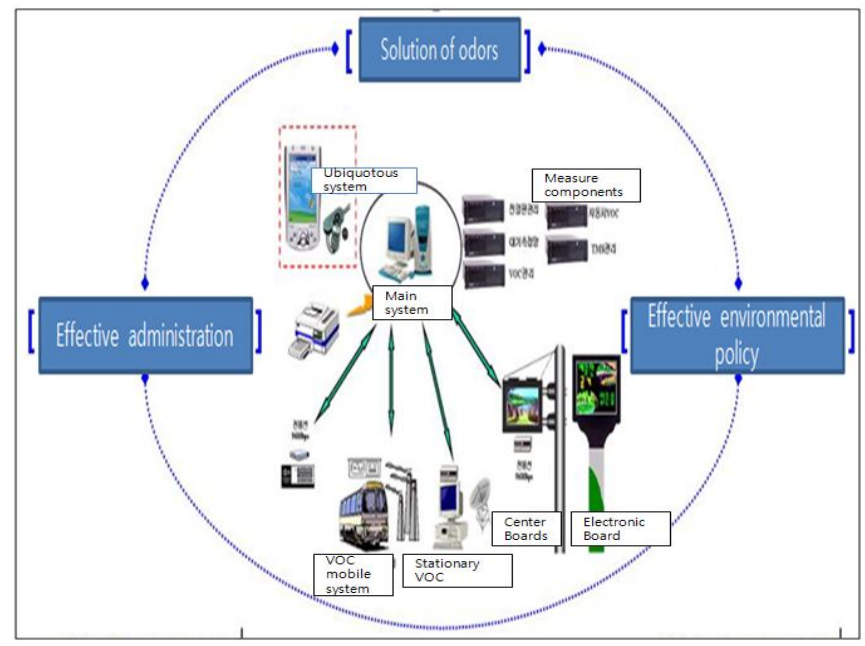

Fig. 2. The ubiquotous monitoring system.

\section{Mobile Samplings with Automobiles}

This system is similar to standard analysis of 22 kinds of odor components, but this system is moved by automobiles like bus. Generally this system is fixed at one place during one month until the all odor components are analyzed completely. Contrary to general analysis of odors, real time countermeasures are not possible but precise analysis in odor emission area is possible with moving conditions.

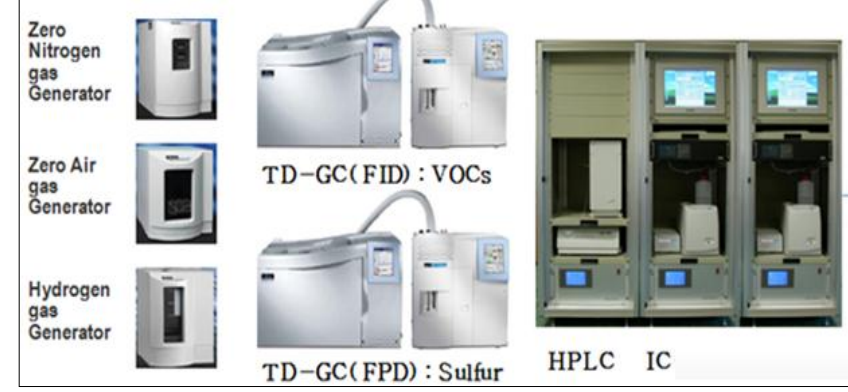

Fig. 3. The labarotory analysis system.

\section{E. Laboratory Analysis}

This is classical method with 22 odor components analysis after sampling on site then, analysis in the laboratory like Fig. 3. We can have more samples than the case of with automobiles, but the samples should be gathered with each component and the sensory analysis must be done separately.

\section{MONITORING IN URBAN AREA}

The graph shown in Fig. 4 is the one sample of aldehydes concentrations measured from on-line monitoring in the one industrial complex in urban area [6].

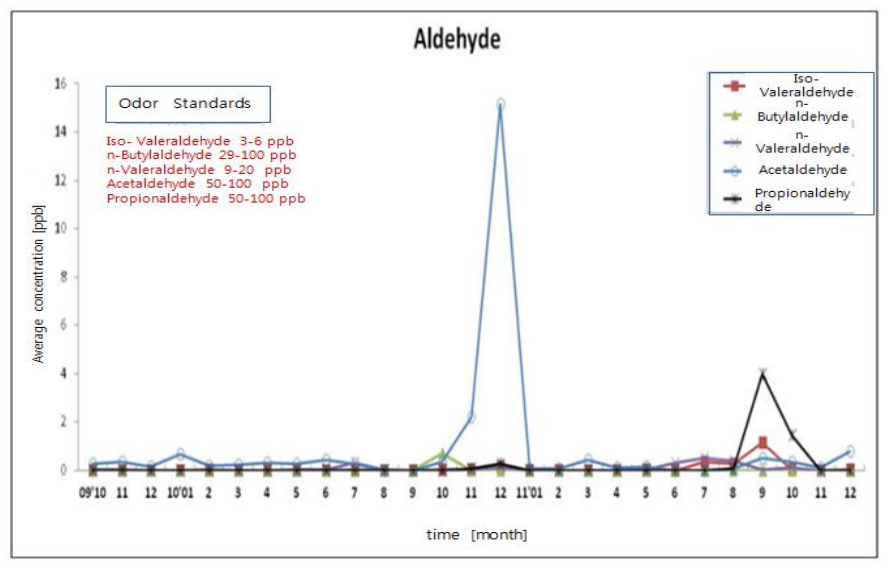

Fig. 4. The on-line signal of aldehydes.

This graph was the data from October 2009 to 2011 which are measured averaged and maximum values. Averaged values of aldehydes group shows below standard concentration, especially acetaldehydes shows 12 to $15 \mathrm{ppbv}$ rise as shown in the Fig. 4.

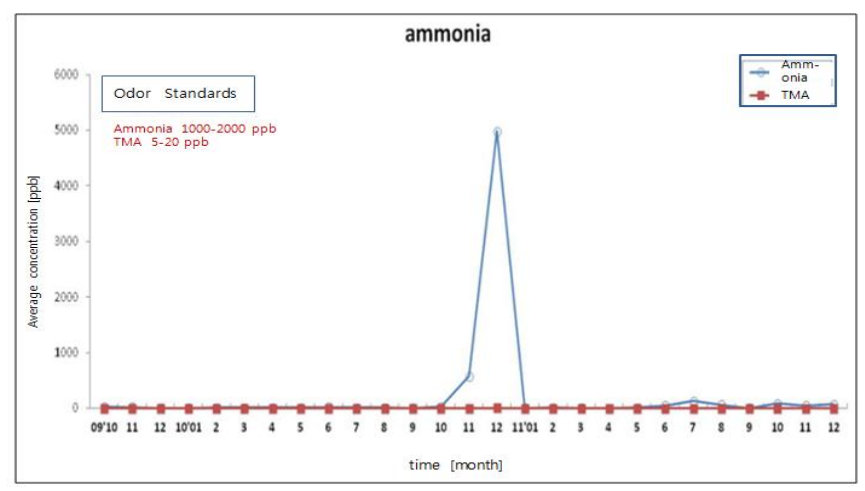

Fig. 5. The on-line signal of ammnonia \& tma

This phenomena may be the impulse type odor or the internal error of instrumental system. Periodical check is 
essential for the accuracy of the data measurement.

The graph shown in Fig. 5 depicts the ammonia and TMA(trimethylamine) concentration measured from on-line monitoring in the one industrial complex in urban area [6]. From this graph it can be shown that the averaged values of ammonia and TMA is below the standard concentration but in December the value of ammonia is unstably high but it cannot be accurately explained with many possible reasons.

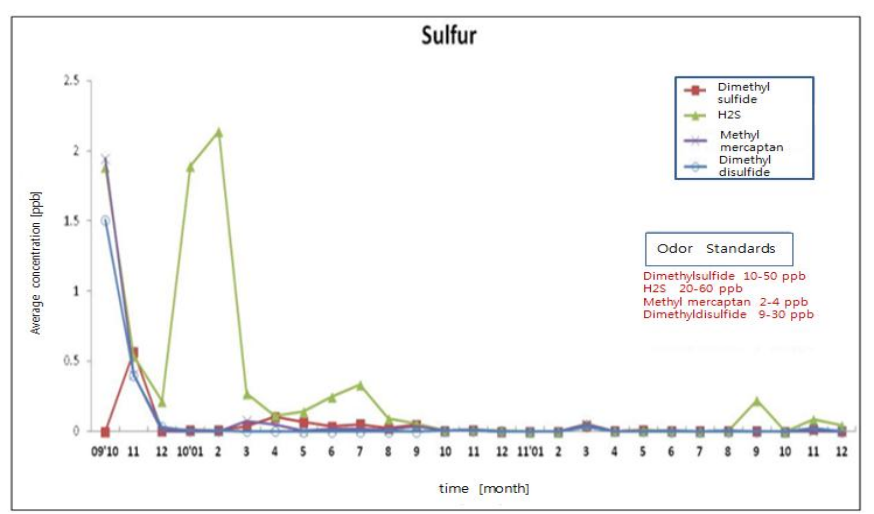

Fig. 6. The on-line signal of surfur compounds.

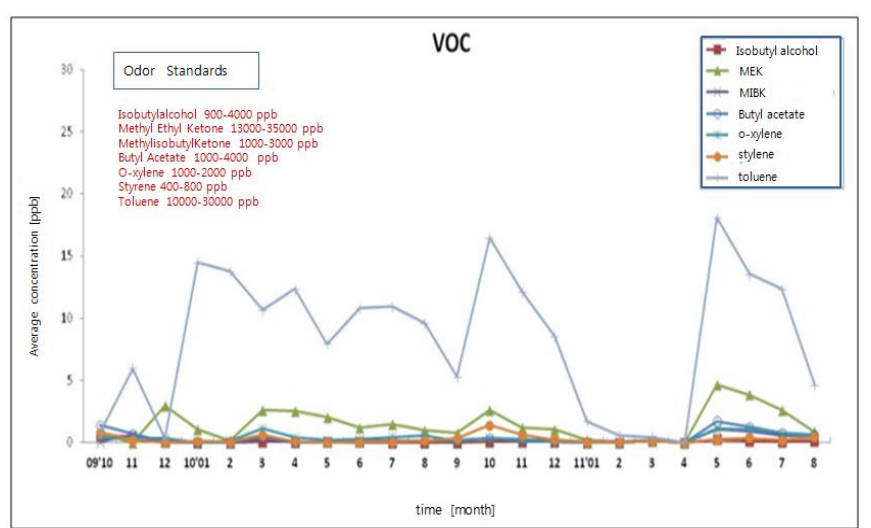

Fig. 7. The on-line signal of volatile organic compounds.

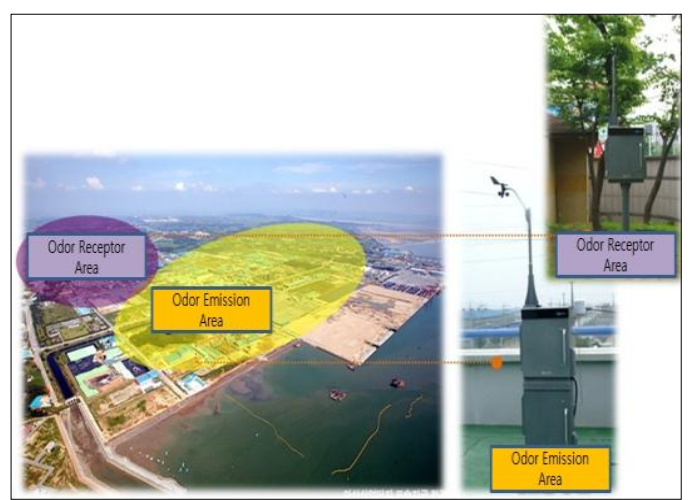

Fig. 8. The map of odor monitoring in korean industrial regions.

The graph shown in Fig. 6 illustrates the sulfur containing compounds concentration measured from on-line monitoring in the one industrial complex in urban area [6]. Sulfur containing compounds means DMS(Dimethyl sulfides), hydrogen sulfides, methyl mercaptan and DMDS(Dimethyl disulfides). From this figure, all sulfur containing compounds did not exceed the standard concentrations within the same period.

The graph shown in Fig. 7 is the volatile organic compounds such as isobutyl alchol, MEK(Methyl Ethyl Ketone), MIK(Methyl Isobutyl Ketone), butyl acetate, o-xylene, styrene and toluene [6].

As it can be seen in the figure, all VOC's showed the concentration below the standard concentrations. Butyl acetate showed the fluctuations through all the measuring time although the scale is not large compared with the standard concentrations. This phenomena may mean that odor can be detected for all day long in those region.

\section{EFFECTIVE MONITORING}

The effective monitoring of odor in urban region would be expressed as follows. The first one is where can we place the monitoring stations, that is to say which place is the most desirable place to detect the suitable positions of civil appeals [7].

And the second one is to check weather conditions such as wind direction and speed or wind rose (wind speed and direction chart). The emission data of main odor generating sources would be desirable for managing odor pollution control in urban region.

Fig. 8 illustrates the odor monitoring in Korean industrial region in odor receptor where people's living districts \& odor emission area where many factories, especially livestock fodder industries are located [3]. This is the type of ubiquitous sensor monitoring system.

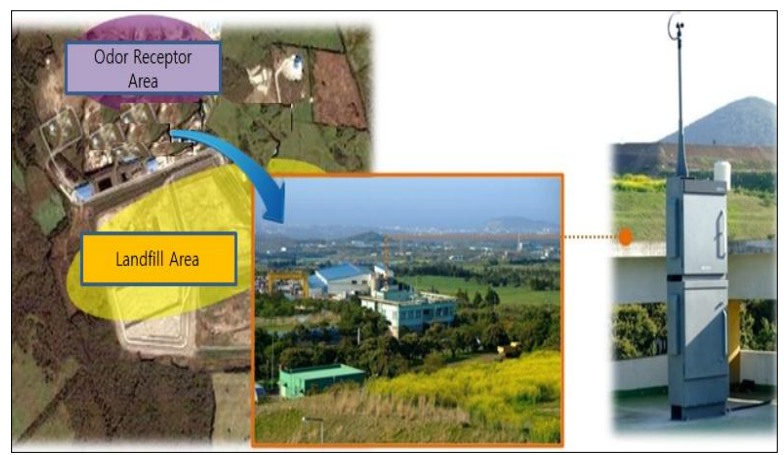

Fig. 9. The map of odor monitoring in korean waste treatment utility near landfill.

Fig. 9 shows the map of odor monitoring in Korean waste treatment utility near landfill regions [3]. Odor receptor area is the region where civil appeals happening due to the odor dispersion from the waste treatment utility near landfill regions. This system was built in 2009, and well operated with rapid and accurate monitoring.

Fig. 10 is the on-line odor monitoring sensor in control device outlet especially biofilter [3].

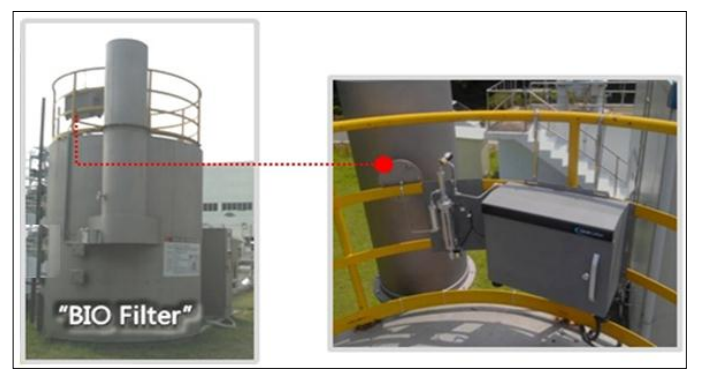

Fig. 10. On-line odor monitoring sensor in control device outlet.

\section{RESULTS AND DISCUSSIONS}

The odor is sensuous pollution by make unpleasant feeling 
to people but the analysis and monitoring is difficult compared to general air pollution in city area.

On-line methods such as ubiquotous monitoring, mobile samplings with automobiles and Laboratory analysis with on-site sampling was explained and compared. Ubiquotous monitoring is used to measure odor concentration of emission sources to make on-line real time management by the government or other managing system.

Mobile samplings with automobiles are similar to standard analysis of 22 kinds of odor components, but this system is moved by automobiles like bus. And laboratory analysis is classical method with 22 odor components analysis after sampling on site then, analysis in the laboratory

The typical odor components were suggested and analyzed. Several examples of on-line monitoring system were suggested to compare several system monitoring plants.

\section{CONCLUSIONS}

A more effective and accurate methods of odor pollution monitoring with on-line mechanism was investigated and compared with conventional sensory dilution method. Operated on-line system in urban area was suggested and explained.

\section{REFERENCES}

[1] K. H. Kim, "A routine on-line analysis of major offensive odorants and assessment of their occurrence mechanisms," KOSAE, Annual Proceedings, pp. 139-145, 2009.

[2] J. B. Kim et al., "A study of analytical method for organic acid compounds [Propionic acid, n-Butylic acid, n-Valeric acid, i-Valerie acid] in ambient air using on-line thermal desorber with GC/FID," KOSAE, vol. 7, pp. 231-237, 2008.

[3] Real-Time Monitoring of Odor Emission Regions, Cases and Methods, Scientific Lab. Center co, LTD, KOSORE Wokshop, pp. 35-50, 2010.

[4] S. J. Park, "A Development of Odor Management System by Real-time Odor Monitoring and Back-trajectory Considering the Characteristic of Odor Emission Sources," Report, Woo Song Univ. 2010.

[5] C. J. Park et al., "The characteristics of indoor \& outdoor environment of school using air dilution olfactory method," KOSAE, Annual Proceedings, 2013.

[6] C. J. Park, A Report on the Master Plan of Odor Management in Incheon Area, Incheon, pp. 102-135, 2012.

[7] C. J. Park, "The study on the civil appeals of odor and effective consciousness of citizen in Incheon Area," KOSAE, vol. 9, pp. 101-107, 2010 .

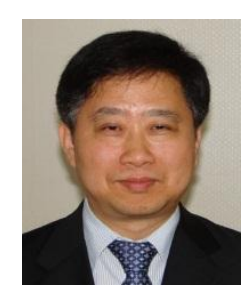

Park Chan Jin graduated from Korea University, and got master and $\mathrm{PhD}$ degrees in same university. His major fields of research are the air pollution control, greenhouse gas technology and odor management technology. His another interests is green growth policy. He is now full-professor in Incheon National University at Urban and Environmental Engineering School. He is member of INU ensemble taking part in piano, Chamber orchestra of his University. 